\title{
Comparison of Postoperative Analgesic Efficacy between Continuous Transversus Abdominis Plane Block, Lumbar Paravertebral and Epidural Blocks after Abdominal Surgeries
}

\author{
Mohamed Elmeliegy \\ Anaesthesia Department, Benha University, Benha, Egypt \\ Email: mohamedfouaaaaad2020@gmail.com
}

How to cite this paper: Elmeliegy, $M$. (2018) Comparison of Postoperative Analgesic Efficacy between Continuous Transversus Abdominis Plane Block, Lumbar Paravertebral and Epidural Blocks after Abdominal Surgeries. Open Journal of Anesthesiology, 8, 267-279.

https://doi.org/10.4236/ojanes.2018.811027

Received: August 10, 2018

Accepted: November 5, 2018

Published: November 8, 2018

Copyright $\odot 2018$ by author and Scientific Research Publishing Inc. This work is licensed under the Creative Commons Attribution International License (CC BY 4.0).

http://creativecommons.org/licenses/by/4.0/

\section{Abstract}

Background: The study was done to assess the postoperative analgesic efficacy of ultrasound-guided continuous transverses abdominis plane block, continuous lumbar paravertebral block and a continuous lumbar epidural block in patients undergoing lower abdominal surgeries (unilateral inguinal hernia repair). We compared their analgesic efficacy over the first 48 hour postoperative, in a randomized, single-blind study in 120 patients divided into four equal groups, 30 patients in each group. Methods: 120 patients randomly assigned into four equal groups, with 30 patients in each group. Group $\mathrm{T}$ received ultrasound-guided transverses abdominis plane block with $20 \mathrm{ml}$ of bupivacaine $0.25 \%$ followed by continuous infusion of bupivacaine $0.125 \%$ $(0.1 \mathrm{ml} / \mathrm{kg} / \mathrm{hr})$ and group $\mathrm{P}$ received ultrasound-guided continuous lumbar paravertebral block with bupivacaine $0.25 \%$ bolus dose $20 \mathrm{ml}$, followed by continuous infusion of bupivacaine $0.125 \%(0.1 \mathrm{ml} / \mathrm{kg} / \mathrm{hr})$. Group E received continuous lumbar epidural infusion of bupivacaine $0.25 \%$ bolus dose $20 \mathrm{ml}$, followed by continuous infusion of bupivacaine $0.125 \%(0.1 \mathrm{ml} / \mathrm{kg} / \mathrm{hr})$ and group $\mathrm{C}$ received normal saline bolus dose $20 \mathrm{ml}$, followed by continuous infusion of normal saline $(0.1 \mathrm{ml} / \mathrm{kg} / \mathrm{hr})$. General anesthesia induced with fentanyl $1-2 \mu \mathrm{g} / \mathrm{kg}$ and propofol $1-3 \mathrm{mg} / \mathrm{kg}$ followed by atracurium $0.5 \mathrm{mg} / \mathrm{kg}$. At the end of the surgical procedure, we activated the regional block with recording of parameters in the postoperative period each patient was assessed for visual analog scale (VAS) at rest and on movement, analgesic consumption, vital signs and presence of complications (nausea, vomiting, sedation), and postoperative patient satisfaction all data collected postoperatively by a blinded investigator at one, two, 6, 12, 24 and 48 hours postoperatively. Results: Postoperative analgesic efficacy is more in group $\mathrm{E}$ than group $\mathrm{P}$ and 
group $\mathrm{T}$, the latter is least effective in pain control. Also in group $\mathrm{E}$ the postoperative analgesic consumption is lower than in group $\mathrm{P}$ and group $\mathrm{T}$, regarding complications as nausea and vomiting more recorded in epidural than the other two groups. Conclusion: Regarding postoperative analgesic efficacy, the continuous lumbar epidural block is more effective than continuous paravertebral and continuous transverses abdominis plane block, but regarding complications, there was a higher incidence in epidural group than other two groups.

\section{Keywords}

Epidural, Paravertebral, TAP Block, Postoperative Analgesia, Ultrasound Guided

\section{Introduction}

In major open abdominal surgeries, such as liver and bowel resection, gastric bypass and gynecological surgery results in moderate to severe pain in the acute postoperative period especially in the first 48 hours despite the use of traditional systemic analgesic techniques, such as patient-controlled analgesia, intramuscular or intravenous opioids and multiple analgesia consist of opioids combined with NSAIDs, acetaminophen, Ketamine and neuropathic agents [1]. Postoperative pain control is essential to prevent patient suffering, early mobilization, faster recovery and decreasing perioperative morbidity associated with thrombotic events and acute coronary events in high-risk patients [2]. In perioperative period, opioids are most commonly used to provide acceptable analgesic, but at the expense of many side effects, so the use of multimodal analgesic regimen is essential. Regional analgesia and anesthesia have shown to supply analgesia and also many benefits which extend beyond the perioperative period [3]. For analgesia following lower abdominal surgeries, a variety of techniques can be used as epidural analgesia which has been shown to be the gold standard and time-tested technique but refusal or contraindications, necessitate the use of other equally good analgesic techniques. Recently different techniques such as TAP block and PVB have emerged as valid alternatives.

Regional pain relieving methods can be used to markedly decrease postoperative pain scores and decrease the utilization of systemic opioids. Local anesthetics can deposited at the peripheral nerve (transversus abdominis plane), the nerve root (paravertebral) and neuraxis (epidural) level. These sites will preferentially block nerve conduction and result in different profiles of analgesia and side effects [4]. Ultrasound (US) guided peripheral nerve block has been reported extensively within the anesthesiology literature and have tried effectively than the standard Landmark techniques [5]. Epidural analgesia can be a helpful technique of pain management in numerous situations. It facilitates could also be clinically further subdivided into anterior, posterior and lateral spaces [6]. 
The spinal nerve within the paravertebral area is submerged within the paravertebral fatty tissue. Paravertebral fascia connects the paravertebral space with the epidural space medially and contralateral paravertebral space. The paravertebral block may be a selective block of the nerve roots at the chosen levels through direct infiltration of the local anesthetic into the spinal nerve and also the medial extension through intervertebral foramina [7].

The transverse abdominis plane (TAP) block designed to provide anesthesia to anterior abdominal wall nerves $\left(\mathrm{T}_{6}\right.$ to $\left.\mathrm{L}_{1}\right)$ was initially represented in 2001 by Rafi as traditional Landmark technique using the lumbar triangle of petit. The local anesthetic injected between the internal oblique and transverse abdominis muscle just deep to fasical layer superficial to it [8]. TAP block was shown to decrease the postoperative opioid consumption, increase the time to initial request for any other analgesia and provide more effective control of pain, however reducing opioid-related undesired effects as postoperative nausea, vomiting, and sedation [9]. The use of ultrasound has allowed anesthesia providers to do the block under direct visualization with greater accuracy. The TAP block is an easy procedure that can be used as an adjuvant for postoperative pain control in surgeries involving $\mathrm{T}_{6}$ to $\mathrm{L}_{1}$ distribution [10].

Anesthesiologists play a significant role in postoperative pain management. For analgesia after lower abdominal surgeries, epidural analgesia, lumbar paravertebral block, and transverse abdominis plane block are suitable options. This study compared the efficacy of ultrasound-guided continuous TAP, lumbar PV and lumbar epidural block in providing postoperative analgesia over $48 \mathrm{~h}$ following lower abdominal surgeries.

\section{Patients and Methods}

After obtaining approval from Benha University Hospital research ethics committee and written informed consent from the patients, we included 120 patients of ASA physical status I, II and III scheduled for lower abdominal surgeries (unilateral inguinal hernia repair) in a randomized, single-blind study during the period from September 2016 to December 2017. We excluded patients with a history of allergy to used drugs or chronic pain, age $<18$ years old or $>60$ years old, coagulopathy, morbid obesity (BMI $>40 \mathrm{~kg} / \mathrm{m}^{2}$ ). Patients were randomly assigned into four groups (group $\mathrm{P})(\mathrm{n}=30)$ patients received ultrasound-guided continuous lumbar paravertebral block with bupivacaine $0.25 \%$ bolus dose $20 \mathrm{ml}$, followed by continuous infusion of bupivacaine $0.125 \%(0.1$ $\mathrm{ml} / \mathrm{kg} / \mathrm{hr})$, (Group $\mathrm{T})(\mathrm{n}=30)$ patients received ultrasound-guided transverse abdominis plane block with $20 \mathrm{ml}$ of bupivacaine $0.25 \%$ followed by continuous infusion of bupivacaine $0.125 \%(0.1 \mathrm{ml} / \mathrm{kg} / \mathrm{hr})$, (Group E) $(\mathrm{n}=30)$ patients received continuous lumbar epidural analgesia with bupivacaine $0.25 \%$ bolus dose $20 \mathrm{ml}$ followed by continuous infusion of bupivacaine $0.125 \%(0.1 \mathrm{ml} / \mathrm{kg} / \mathrm{hr})$ and (Group C) $(\mathrm{n}=30)$ patients in this group received saline injections paravertebrally $(n=10)$, in the TAP $(n=10)$ and epidurally $(n=10)$. The volume of saline 
delivered to each group was identical to that suggested for each block.

Randomization was done by random number list which generated by online program randomization numbers were concealed in opaque envelops which were opened by the investigator. The patients and postoperative care staff were blinded to group arrangement. All study patients received standard pre and intraoperative monitoring. General anesthesia induced with fentanyl $1-2 \mu \mathrm{g} / \mathrm{kg}$ and propofol $1-3 \mathrm{mg} / \mathrm{kg}$ followed by atracurium $0.5 \mathrm{mg} / \mathrm{kg}$ to facilitate endotracheal intubation all patients artificially ventilated, and maintenance of anesthesia was achieved by the inhalation of isoflurane /air $/ \mathrm{O}_{2}$ mixture and atracurium $0.1 \mathrm{mg} / \mathrm{kg}$ as a maintenance dose every 30 minutes till the end of the procedure. Insertion of lumbar paravertebral catheter/lumbar epidural catheter was done before induction of general anesthesia, while the transverses abdominis plane block was performed under general anesthesia.

In the paravertebral group, standard regional anesthesia tray prepared with the followings: sterile towels, gloves, $20 \mathrm{ml}$ syringes with local anesthetic, 25-gauge needle for skin infiltration, an 18 gauge $8 \mathrm{~cm}$ epidural needle (perfix. B. Braun Melsungen AG), syringe pump (Fresenius Kabi) and GE LOGIQP ${ }_{5}$ ultrasound machine (with 5 - $12 \mathrm{MHz}$ Probe and Colour Doppler Imaging Capability). In sitting position after skin sterilization and protection of ultrasound probe with a sterile probe cover, a 5 - $8 \mathrm{MHz}$ curved array ultrasound transducer probe placed over a spinous process in the mid-line in a longitudinal fashion to identify lumbar paravertebral space. The probe then moved $2-3 \mathrm{~cm}$ laterally from the midline, to visualize transverse processes and the wedge-shaped paravertebral space. The best views of paravertebral space obtained with a slight oblique tilt of the transducer.

Once the best image of the space captured, $4-6 \mathrm{ml}$ of local anesthetic (lidocaine 1\%) infiltered subcutaneously, an 18 gauge $8 \mathrm{~cm}$ epidural needle was utilized to identify the space, the needle tip advanced under direct vision. Correct position confirmed by saline injection and observation of paravertebral space distention. A 20 gauge multipoles epidural catheter (B. Braun) was inserted $4 \mathrm{~cm}$ beyond the needle tip after the catheter secured in place and negative aspiration, a test dose of $4 \mathrm{ml}$ of lidocaine mixed with epinephrine 1:200,000 given.

In TAP block group, after skin sterilization and protection of ultrasound probe with sterile probe cover, ultrasound linear array probe was placed to abdomen transversally between the iliac crest and the costal margin in midaxillary line (the triangle of petit). After three muscle layers seen clearly, an 18 gauge 8 $\mathrm{cm}$ epidural needle inserted in a sagittal plane approximately $3-4 \mathrm{~cm}$ medial to the probe (in-plane technique). The probe was moved slightly anterior to visualize skin puncture and superficial course, then probe moved gradually posterior to the midaxillary line position, following the needle to correct position in transverse abdominis plane $1 \mathrm{ml}$ of local anesthetic was injected to open the plane followed by injection of the $20 \mathrm{ml}$ of bupivacaine $0.25 \%$. A multipole $20 \mathrm{G}$ epidural catheter inserted where $3-5 \mathrm{~cm}$ of the catheter left inside the plane; 
then the catheter taped to the skin.

In the lumbar epidural group, low frequency $(5 \mathrm{MHz})$ curved array probe placed $3-4 \mathrm{~cm}$ lateral to the midline in the parasagittal plane (Ps) then probe moved from lateral to medial direction toward the median sagittal plane. The laminae of the lumbar vertebrae appear as "sawteeth" pattern. The interposing gaps denote the paramedian interlaminar spaces, through which the following structures visualized in the following arrangement from superficial to deep: ligamentum flavum, epidural space, posterior dura mater, anterior dura, posterior longitudinal ligament, and posterior vertebral body. Once sagittal plane examination completed, the probe rotated 90 degrees into transverse orientation an centered on the midline. Superficial hyperechoic line with acoustic shadowing beneath appear on the screen which represent the tip of spinous process, sliding the probe in candal or cephalic direction provide interlaminar view of the vertebral canal contents depending on the angle at which spinous process project and the width of inter-spinous space, the transducer with tilted cephalad to optimize vertebral canal image. The tilt (inclination) of the transducer and the depth of the epidural space is measured, mark the interspace on the skin and the insertion point infiltered with lidocaine $1 \%$ remove all the gel with dry gauze and then proceed for placement of epidural catheter using an 18 gauge $8 \mathrm{~cm}$ epidural needle and a 20 gauge multipoles catheter inserted 5 $\mathrm{cm}$ beyond the loss of resistance after securing the catheter and negative aspiration, a test dose given with $4 \mathrm{ml}$ of lidocaine $1 \%$ mixed with epinephrine $1: 200,000$.

After surgery and extubation, the patients transferred to the recovery room, and infusion started plus standardized analgesic regimen consisting of regular I.V paracetamol $1 \mathrm{~g}$ every 6 hours combined with morphine $(5 \mathrm{mg})$ given when pain score equal to or greater than 4 . If any catheter was ineffective (pain not controlled) in the recovery area, then we re-site it, if patient continued to complain of pain following resiting of catheters, we remove the catheter and start pain control with a patient-controlled analgesia (PCA) device containing morphine and this considered case failure and excluded from the study.

The visual analog scale (VAS), morphine consumption, nausea vomiting, and drowsiness were assessed by an investigator in the PACU at $0,1,2,6,12,24$ and $48 \mathrm{~h}$ postoperatively. All patients were asked to give scores of their pain at rest and on movement (knee flexion) at each time point. Pain severity was measured using the visual analog scale (VAS, $10 \mathrm{~cm}$ line in which $0 \mathrm{~cm}=$ no pain and 10 $\mathrm{cm}=$ worst pain imaginable). 48 hours after surgery, patients were asked to document their satisfaction with postoperative pain control regimen using a scoring system ( 1 = satisfied, $2=$ cannot answer, $3=$ dissatisfied $)$.

Visual analoge scale (VAS) and $48 \mathrm{~h}$ morphine consumption is the primary outcomes measure in this study. While vital signs and side effects associated with morphine consumption were the secondary outcomes.

Statistical analyses performed using a standard statistical program (SPSS ver- 
sion 16). Quantitative data were presented as a mean \pm standard deviation, and analyzed by using one way ANOVA test, while qualitative data were presented as numbers and percentages and analyzed by using chi-square test, $\mathrm{p}$-value $<0.05$ was considered statistically significant, $\mathrm{p}$-value $<0.01$ was considered statistically highly significant.

\section{Results}

Demographic data showed no difference regarding age, ASA physical status, body mass index (BMI) or duration of surgery between groups (Table 1).

VAS was measured at rest and on patient's movement (Knee Flexion), at PACU, 1, 2, 6, 12, 24 and 48 hours postoperatively (Figure 1).

All forms of block, transverses abdominal plane, paravertebral and epidural significant reduce pain scores (VAS) at nearly all time intervals except at PACu time during the first 48 hours following surgery. Postoperative pain intensity (VAS score) on coughing was also significantly decreased in all forms of block compared with placebo, while epidural was significantly more effective than other two types of block at many time intervals (Table 2).

During the first 48 hours in the post-operative period, the total analgesic consumption by morphine boluses used in each group (When VAS $\geq 4$ ) despite the maximum rate of bupivacaine infusion, rescue analgesia $5 \mathrm{mg}$ bolus of morphine was intravenously administrated to achieve pain relief was repeated every 4 hours as needed, this showed a highly significant difference between groups (P-value $<0.001)$. As expressed as mean $\pm \mathrm{SD}$, in group C $14.83 \pm 2.78$, in group $\mathrm{T}$, it is $11.17 \pm 3.64$, in group $P$ it is $7.5 \pm 3.41$, and in group $\mathrm{E}$ it is $7.17 \pm 3.4$ (Figure 2).

All methods of the block provided sufficient degree of patient satisfaction, while only $50 \%$ of control group patients showed that they were satisfied (Table 3).

The mean arterial pressure (MAP), its levels were slightly higher in the control group than others. Group P, T show no significant difference from baseline values, except for a slight decrease in group $\mathrm{P}$, but in group $\mathrm{E}$, there was a significant decrease in the MAP from the first hour after bolus dose till the end of the study. No significant changes during the study period between groups regarding heart rate, but in group E, heart rate was significantly higher than baseline during the study.

Regarding complications, in group C, nausea was 11 patients (37\%), vomiting was 5 patients (17\%), and drowsiness were 5 patients (17\%). In group T, 7 patients $(23 \%)$ had nausea and vomiting in 1 patient $(3 \%)$ and drowsiness in 3 patients (10\%). In group $\mathrm{P}$, nausea occurred in 8 patients (27\%), vomiting in 2 patients $(6 \%)$ and drowsiness in 3 patients (10\%). In group E, nausea was 9 patients $(30 \%)$, vomiting in 3 patients (10\%) and drowsiness in 2 patients $(6 \%)$, with no statistically significant difference between groups regarding complications. 


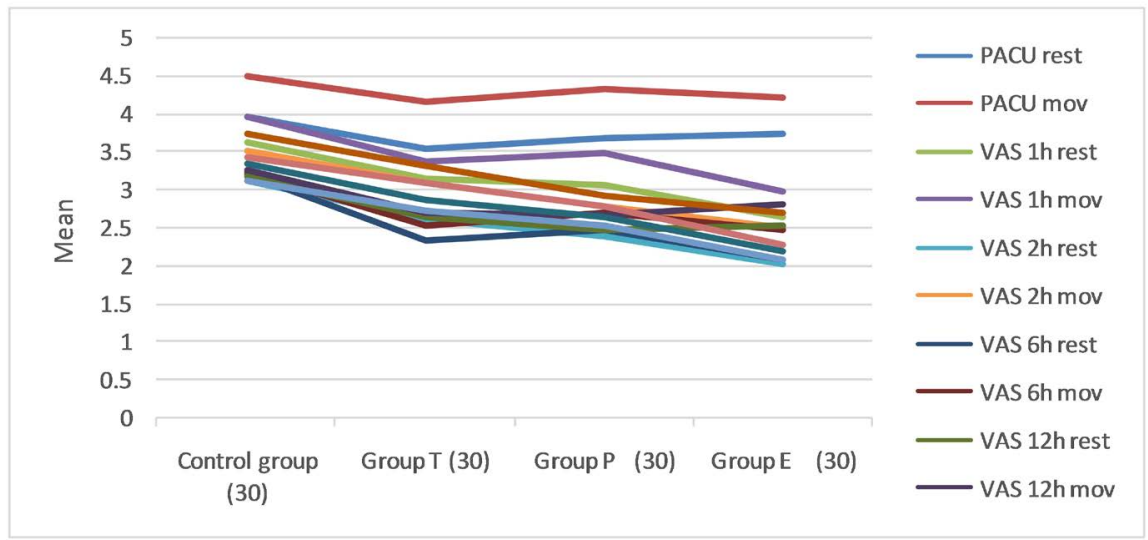

Figure 1. VAS values at rest and on patient's movement.

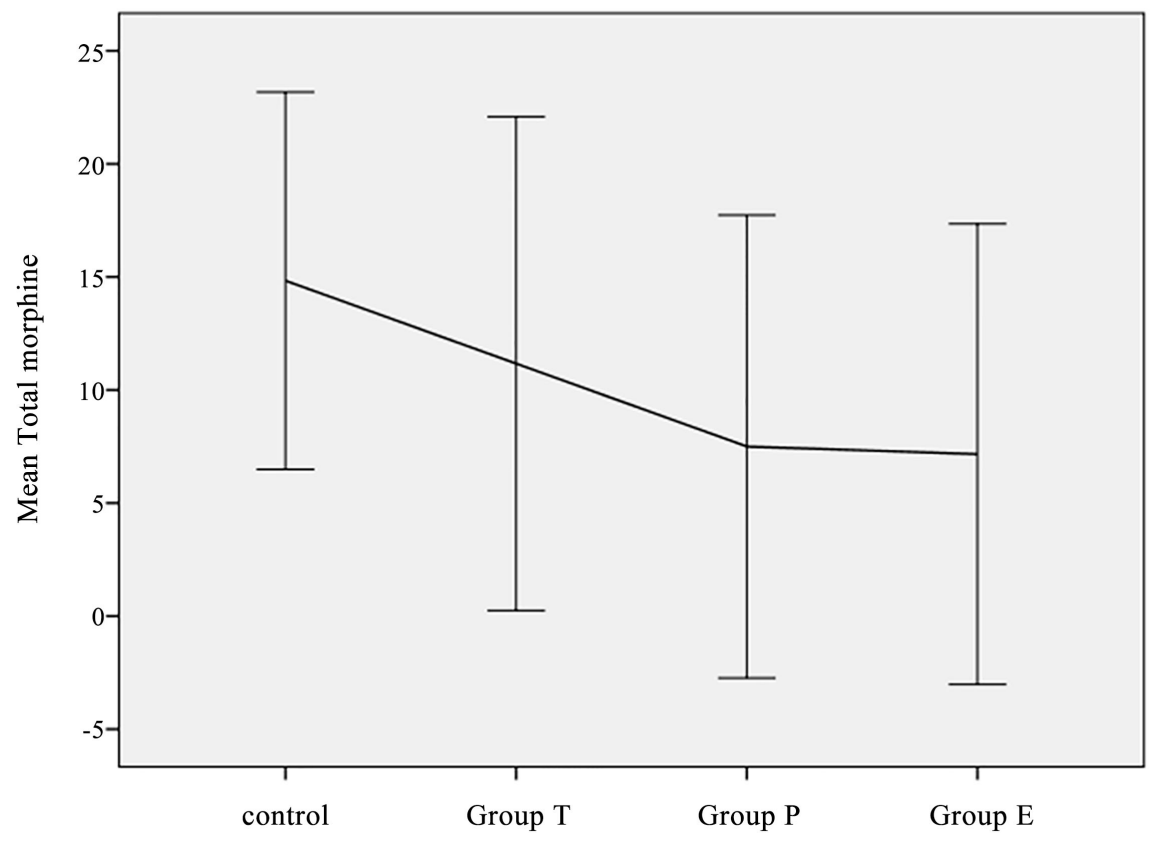

Error bars: +/- $3 \mathrm{SD}$

Figure 2. Total analgesic consumption (morphine $\mathrm{mg} / 24 \mathrm{~h}$ ).

Table 1. Demographic data and duration of surgery in all groups.

\begin{tabular}{ccccccc}
\hline & $\begin{array}{c}\text { Group C } \\
(30) \\
\text { Mean } \pm \text { SD }\end{array}$ & $\begin{array}{c}\text { Group T (30) } \\
\text { Mean } \pm \text { SD }\end{array}$ & $\begin{array}{c}\text { Group P } \\
\text { (30) } \\
\text { Mean } \pm \text { SD }\end{array}$ & $\begin{array}{c}\text { Group E } \\
\text { (30) } \\
\text { Mean } \pm \text { SD }\end{array}$ & F test & $p$-value \\
\hline Age & $41.3 \pm 9.98$ & $39.07 \pm 10.49$ & $40.40 \pm 10.86$ & $40.83 \pm 7.90$ & 0.29 & 0.84 \\
ASA & $1.7 \pm 0.70$ & $1.43 \pm 0.68$ & $1.73 \pm 0.69$ & $1.73 \pm 0.69$ & 1.33 & 0.27 \\
BMI & $32.04 \pm 4.79$ & $32.34 \pm 4.93$ & $33.6 \pm 4.72$ & $34.43 \pm 4.46$ & 0.18 & 0.25 \\
$\begin{array}{c}\text { Duration of } \\
\text { surgery }\end{array}$ & $78.33 \pm 9.44$ & $77.3 \pm 11.87$ & $76.17 \pm 10.74$ & $78.17 \pm 11.27$ & 0.86 \\
\hline
\end{tabular}

$\mathrm{C}=$ Control group, $\mathrm{T}=$ Transversus abdominis plane block, $\mathrm{P}=$ Paravertebral block, $\mathrm{E}=$ Epidural block, Data presented as mean $\pm \mathrm{SD} . \mathrm{P}$-value $<0.05=$ significant, P-value $<0.01=$ highly significant. 
Table 2. Visual analog scale in all groups during 48 hours postoperative.

\begin{tabular}{ccccccc}
\hline $\begin{array}{c}\text { Postoperative } \\
\text { visual analog scale }\end{array}$ & $\begin{array}{c}\text { Group C (30) } \\
\text { Mean } \pm \text { SD }\end{array}$ & $\begin{array}{c}\text { Group T } \\
(30) \\
\text { Mean } \pm \text { SD }\end{array}$ & $\begin{array}{c}\text { Group P } \\
\text { (30) } \\
\text { Mean } \pm \text { SD }\end{array}$ & $\begin{array}{c}\text { Group E } \\
\text { Mean } \pm \text { SD }\end{array}$ & F test & p-value \\
\hline PACU rest & $3.97 \pm 0.96$ & $3.53 \pm 1.04$ & $3.67 \pm 0.88$ & $3.73 \pm 1.11$ & 0.98 & 0.41 \\
PACU movement & $4.5 \pm 0.94$ & $4.17 \pm 1.34$ & $4.33 \pm 1.32$ & $4.23 \pm 1.5$ & 0.38 & 0.77 \\
VAS 1 h rest & $3.63 \pm 0.93$ & $3.13 \pm 0.82 \mathrm{a}$ & $3.07 \pm 0.64 \mathrm{a}$ & $2.63 \pm 0.81 \mathrm{abc}$ & 7.76 & $0.001^{* *}$ \\
VAS 1 h movement & $3.97 \pm 1.22$ & $3.37 \pm 1.33 \mathrm{a}$ & $3.47 \pm 0.90$ & $2.97 \pm 1.0 \mathrm{a}$ & 4.02 & $0.009^{* *}$ \\
VAS 2 h rest & $3.13 \pm 0.78$ & $2.63 \pm 0.67 \mathrm{a}$ & $2.40 \pm 0.50 \mathrm{a}$ & $2.03 \pm 0.41 \mathrm{abc}$ & 17.34 & $0.001^{* *}$ \\
VAS 2h movement & $3.5 \pm 1.31$ & $3.07 \pm 1.26$ & $2.77 \pm 0.68 \mathrm{a}$ & $2.5 \pm 0.97 \mathrm{ab}$ & 4.70 & $0.004^{* *}$ \\
VAS 6 h rest & $3.20 \pm 0.81$ & $2.33 \pm 0.66 \mathrm{a}$ & $2.35 \pm 0.51 \mathrm{a}$ & $2.07 \pm 0.52 \mathrm{a}$ & 17.49 & $0.001^{* *}$ \\
VAS 6 h movement & $3.23 \pm 1.22$ & $2.53 \pm 1.25 \mathrm{a}$ & $2.70 \pm 0.65$ & $2.47 \pm 0.97 \mathrm{a}$ & 3.27 & $0.024^{*}$ \\
VAS 12 h rest & $3.17 \pm 0.83$ & $2.63 \pm 0.67 \mathrm{a}$ & $2.47 \pm 0.57 \mathrm{a}$ & $2.53 \pm 1.01 \mathrm{a}$ & 4.90 & $0.003^{* *}$ \\
VAS 12 h movement & $3.27 \pm 1.20$ & $2.70 \pm 1.34$ & $2.67 \pm 0.71$ & $2.80 \pm 1.13$ & 1.85 & 0.14 \\
VAS 24 h rest & $3.33 \pm 0.88$ & $2.87 \pm 0.97 \mathrm{a}$ & $2.63 \pm 0.62 \mathrm{a}$ & $2.20 \pm 1.06 \mathrm{ab}$ & 8.27 & $0.001^{* *}$ \\
VAS 24 h movement & $3.73 \pm 1.29$ & $3.30 \pm 1.42$ & $2.93 \pm 0.79 \mathrm{a}$ & $2.70 \pm 1.09 \mathrm{ab}$ & 4.48 & $0.005^{* *}$ \\
VAS 48 h rest & $3.13 \pm 0.78$ & $2.73 \pm 0.87 \mathrm{a}$ & $2.53 \pm 0.57 \mathrm{a}$ & $2.07 \pm 0.87 \mathrm{abc}$ & 9.69 & $0.001^{* *}$ \\
VAS 48 h movement & $3.43 \pm 1.25$ & $3.10 \pm 1.37$ & $2.77 \pm 0.68 \mathrm{a}$ & $2.27 \pm 0.98 \mathrm{ab}$ & 6.10 & $0.001^{* *}$ \\
\hline
\end{tabular}

Data presented as mean $\pm \mathrm{SD}{ }^{* *}$ highly significant ${ }^{*}$ significant. $\mathrm{C}=$ Control group, $\mathrm{T}=$ Transversus abdominis plane block, $\mathrm{P}=\mathrm{Paravertebral}$ block, $\mathrm{E}=$ Epidural block, Data presented as mean $\pm \mathrm{SD}$. P-value $<0.05=$ significant, $\mathrm{P}$-value $<0.01=$ highly significant.

Table 3. Total pain rescue analgesic consumption during 48 hours and patients satisfaction.

\begin{tabular}{ccccccc}
\hline & $\begin{array}{c}\text { Group C } \\
(\mathbf{3 0})\end{array}$ & Group T (30) & $\begin{array}{c}\text { Group P } \\
\mathbf{( 3 0 )}\end{array}$ & $\begin{array}{c}\text { Group E } \\
(\mathbf{3 0})\end{array}$ & Test & $p$-value \\
\hline Total morphine & $14.83 \pm 2.78$ & $11.17 \pm 3.64 \mathrm{a}$ & $7.50 \pm 3.41 \mathrm{ab}$ & $7.17 \pm 3.40 \mathrm{ab}$ & F test $=35.24$ & $0.001^{\star *}$ \\
Satisfied & $15(50.0)$ & $23(76.7)$ & $24(80.0)$ & $26(86.7)$ & X2 $=11.93$ & $0.008^{\star *}$ \\
Can't answer & $4(13.3)$ & $5(16.7)$ & $4(13.3)$ & $3(10.0)$ & FET $=0.68$ & 0.98 \\
Dissatisfied & $11(36.7)$ & $2(6.7)$ & $2(6.7)$ & $1(3.3)$ & FET $=15.17$ & $0.001^{\star *}$ \\
\hline
\end{tabular}

${ }^{*}$ Highly significant. $\mathrm{C}=$ Control group, $\mathrm{T}=$ Transversus abdominis plane block, $\mathrm{P}=$ Paravertebral block, $\mathrm{E}=$ Epidural block, Data presented as mean $\pm \mathrm{SD}$. P-value $<0.05=$ significant, $\mathrm{P}$-value $<0.01=$ highly significant.

\section{Discussion}

Postoperative pain, particularly once poorly controlled, could produce a range of acute (i.e., adverse physical responses) and chronic effects (i.e., chronic pain, delayed long-term recovery). Poor postoperative pain control can lead to many adverse outcomes such as hypertension, cardiac arrhythmias, myocardial ischemia, immobility, deep venous thrombosis, poor wound healing and reduce alveolar ventilation [11]. Many choices are available for postoperative pain control, including regional analgesic techniques (i.e., peripheral and neuraxial) and systemic analgesics (NSAIDs and opioids). Addition of different analgesics that act at different nervous system sites and by different mechanisms leading to additive and/or synergistic effect with lowered adverse effects that is what is recently 
called multimodal analgesia [12].

This study was carried out at Benha University; to compare efficacy of ultrasound-guided transverses abdominis plane block, continuous lumbar paravertebral block and lumbar epidural block on postoperative analgesia and complications in patients undergoing abdominal surgeries, in which 120 patients included in a prospective single-blinded randomized clinical study in the form of four groups 30 patients in each group. The primary targets of this study were visual analog scale (VAS) for pain at rest and on movement postoperatively and measuring the mean morphine consumption in 48 hours. The secondary targets include vital signs in the form of heart rate, mean arterial blood pressure and respiratory rate at PACU every 15 minutes in the first hour then after two hours, 6 hours, 12, 24, 48 hours postoperatively, time of operation and complications (nausea, vomiting, sedation).

As regard visual analog scale (VAS) and mean morphine consumption. Current study showed significant differences between groups and control as regards VAS and these were increased mean morphine consumption in the first 48 hours postoperatively in group $\mathrm{T}$ compared with group $\mathrm{P}$ and group $\mathrm{E}$, this is in agreement with Pankaj N Surange [13] who compared continuous lumbar paravertebral with continuous epidural block, they found that both routes were effective in postoperative pain control and didn't significantly differ, the same with Messina et al. [14], who compared epidural versus paravertebral blockade in thoracic surgery. They founded no significant differences in VAS score between groups at any time point, but values were lower in epidural than the paravertebral group at 6,24, 48 hours postoperatively.

Two other studies [15] [16] were in consistent with research, first found that no difference in pain intensity before and after respiratory physiotherapy in the epidural and paravertebral group, the second documented no difference in postoperative pain in days 1 - 3 between the two groups. Tornero-Campello G. [17], who compared intravenous PCA with morphine, TEA and TAP block in laparoscopic high anterior resection, recorded that cumulative opioid use was significantly lower for the epidural group at all time points up to discharge than PCA group and up to $72 \mathrm{~h}$ significantly lower than for TAP group but length of hospital stay was longer in the TEA group (6 days) than in TAP group (4 days). Lin Y-N et al. [18] showed higher morphine consumption postoperatively in patients received TAP block than those received paravertebral block.

Federico et al. [19] found statistical significance in VAS in favor of the paravertebral group in relation to the epidural group when comparing analgesia in patients undergoing thoracotomy. But this mostly due to higher local anesthetic concentration in the paravertebral group and the length of surgery was 108.6 minutes for PA group and 141.3 minutes for EA group $(\mathrm{P}<0.0001)$. Our results also not consistent with Debreceni study [20] who compared continuous paravertebral and epidural analgesia following thoracotomy and recorded the lower pain score in continuous epidural than continuous paravertebral in the early 
postoperative period (up to $12 \mathrm{~h}$ postoperatively only) but the large volume can explain this. Injected into epidural space $(0.2 \mathrm{ml} / \mathrm{kg})$. Others who [21] studied different regional techniques for inguinal hernia repair, comparing TAP block (continuous bupivacaine infusion $0.25 \%$ at rate $8 \mathrm{ml} / \mathrm{hr}$ ) and paravertebral block (continuous infusion of $0.125 \%$ bupivacaine at rate $8 \mathrm{ml} / \mathrm{hr}$ ). They observed similar analgesic efficacy could be achieved with both blocks and either technique can be used for uni or bilateral abdominal surgery to produce satisfactory analgesia in combination with paracetamol, NSAIDs and morphine PCA. This can be explained by the lower concentration of bupivacaine in the paravertebral group than TAP block group besides increased failure rate of catheter insertion with the paravertebral group than with TAP group. Also, Niraj et al. [22] studied the patients undergoing laparoscopic bowel resections, the 70 cases randomized to treated with continuous TAP block or continuous epidural analgesia; they found no difference at $24 \mathrm{~h}$ during coughing postoperative in the median VAS and no difference in tramadol consumption between groups.

As regards the mean arterial pressure (MAP), its levels are slightly higher in control group than others group $\mathrm{P}, \mathrm{T}$ show no significant difference from baseline values, except for slight decrease in group $\mathrm{P}$, but in group E, there is significant decrease in MAP from the first hour after bolus dose till end of the study. No significant changes during the study period between groups regarding heart rate, but in group $\mathrm{E}$, heart rate were significantly higher than baseline during the study. This can be explained by hypotension, also in group $\mathrm{P}$ these are unilateral sympathetic block compared to bilateral block in group E. A systemic review and met-analysis [23] from eight trials studied analgesic safety and efficacy of thoracic epidural and paravertebral analgesic during thoracotomy, found that TEA associated with significantly higher hypotension than PVB in both intra and postoperative period. Other two studies [19] [24] comparing epidural and TAP analgesia in 44 patients undergoing laparotomy surgeries, TAP group showed a less reduction in mean blood pressure and reduced the frequency of hypotension than in epidural group due to epidural group sympathetic block. Santhosh and Rajendran [25], found no significant difference in the MAP between two groups and no decrease in blood pressure after the first hour. This can be explained by; only $8 \mathrm{ml}$ bolus of $0.25 \%$ bupivacaine after the end of surgical procedure and patient not receive opioid analgesic intraoperatively while intraoperative analgesia maintained only with $\mathrm{N}_{2} \mathrm{O}$.

Regarding complications, in group C, nausea was 11 patients (37\%), vomiting was 5 patients (17\%), and drowsiness were 5 patients (17\%). In group $\mathrm{T}$ patients (23\%) had nausea, and vomiting in 1 patient (3\%) and drowsiness in 3 patients (10\%). In group $\mathrm{P}$, nausea occurred in 8 patients (27\%), vomiting in 2 patients (6\%) and drowsiness in 3 patients (10\%). In group, E nausea was 9 patients (30\%) vomiting in 3 patients (10\%) and drowsiness in 2 patients (6\%). With no statistically significant difference between groups regarding the complications a meta-analysis [26], analyzed side effects as nausea, vomiting, hypotension and 
pulmonary complications. Found that PVB compared to EPI resulted in significantly less incidence of urinary retention, nausea, vomiting, and hypotension.

Limitations of our study; the study didn't include the regional anesthesia procedure time (i.e., time from positioning the patient to fixation of the catheter) and we also did not record the number of trials of each form of the block to assess block difficulty.

\section{Conclusion}

Regarding postoperative analgesia continuous lumbar epidural block is more effective than continuous transverses abdominis plane block and continuous paravertebral block, but regarding complications (hypotension, nausea, and vomiting) there were higher incidence of complications in patients received epidural analgesia than in other groups; however, TAP block can be alternative postoperative analgesic technique for patients in which epidural and paravertebral blocks are contraindicated.

\section{Conflicts of Interest}

The authors declare no conflicts of interest regarding the publication of this paper.

\section{References}

[1] Marandola, M., Cilli, T., Alessandri, F., et al. (2008) Perioperative Management in Patients Undergoing Pancreatic Surgery: The Anesthesiologist's Point of View. Transplantation Proceedings, 40, 1195-1199.

https://doi.org/10.1016/j.transproceed.2008.03.114

[2] Yeager, M.P., Glass, D.D., Neff, R.K. and Brinck-Johnsen, T. (1987) Epidural Anesthesia and Analgesia in High-Risk Surgical Patients. Anesthesiology, 66, 729-736. https://doi.org/10.1097/00000542-198706000-00004

[3] Tuman, K.J., McCarthy, R.J., March, R.J., DeLaria, G.A., Patel, R.V. and Ivankovich, A.D. (1991) Effects of Epidural Anesthesia and Analgesia on Coagulation and Outcome after Major Vascular Surgery. Anesthesia \& Analgesia, 73, 696-704. https://doi.org/10.1213/00000539-199112000-00005

[4] Le-Wendling, L., Nin, O. and Capdevila, X. (2015) Cancer Recurrence and Regional Anesthesia: The Theories, the Data, and the Future in Outcomes. Pain Medicine, 17, 756-775. https://doi.org/10.1111/pme.12893

[5] Chan, V.W. (2003) Applying Ultrasound Imaging to Interscalene Brachial Plexus Block. Regional Anesthesia and Pain Medicine, 28, 340-343. https://doi.org/10.1016/S1098-7339(03)00189-5

[6] Jagla, G., Walocha, J., Rajda, K., et al. (2009) Anatomical Aspects of Epidural and Spinal Analgesia. Advances in Palliative Medicine, 8, 135-146.

[7] Karmakar, M.K., Gin, T. and Ho, A.M. (2001) Ipsilateral Thoraco-Lumbar Anesthesia and Paravertebral Spread after Low Thoracic Paravertebral Injection. British Journal of Anaesthesia, 87, 312-316. https://doi.org/10.1093/bja/87.2.312

[8] Petersen, P.L., Mathiesen, O., Torup, H. and Dahl, J.B. (2010) The Transversus Abdominis Plane Block: A Valuable Option for Postoperative Analgesia. A Topical Review. Acta Anaesthesiologica Scandinavica, 54, 529-535. 
https://doi.org/10.1111/j.1399-6576.2010.02215.x

[9] Siddiqui, M.R., Sajid, M.S., Uncles, D.R., Cheek, L. and Baig, M.K. (2011) A Meta-Analysis on the Clinical Effectiveness of Transversus Abdominis Plane Block. Journal of Clinical Anesthesia, 23, 7-14. https://doi.org/10.1016/j.jclinane.2010.05.008

[10] Aveline, C., Le Hetet, H., Le Roux, A., Vautier, P., Cognet, F., Vinet, E., et al. (2011) Comparison between Ultrasound-Guided Transversus Abdominis Plane and Conventional Ilioinguinal/Iliohypogastric Nerve Blocks for Day-Case Open Inguinal Hernia Repair. British Journal of Anaesthesia, 106, 380-386. https://doi.org/10.1093/bja/aeq363

[11] Vadivelu, N., Mitra, S. and Narayan, D. (2010) Recent Advances in Postoperative Pain Management. Yale Journal of Biology and Medicine, 83, 11-25.

[12] Elviret-Lazo, O.L. and White, P.F. (2010) Postoperative Pain Management after Ambulatory Surgery: Role of Multimodal Analgesia. Anesthesiology Clinics, 28, 217-224.

[13] Surange, P.N., Chadalavada, B. and Mohan, V.R. (2012) Comparative Evaluation of Continuous Lumbar Paravertebral versus Continuous Epidural Block for Post-Operative Pain Relief in Hip Surgeries. Anesthesiology and Pain Medicine, 1, 178-183. https://doi.org/10.5812/kowsar.22287523.3348

[14] Messina, M., Boroli, F., Landoni, G., Bignami, E., et al. (2009) A Comparison of Epidural vs. Paravertebral Blockade in Thoracic Surgery. Minerva Anestesiologica, 75, 616-621.

[15] Pintaric, T.S., Potocnik, I., Hadzic, A., Stupnik, T., Pintaric, M. and Novak, J.V. (2011) Comparison of Continuous Thoracic Epidural with Paravertebral Block on Perioperative Analgesia and Hemodynamic Stability in Patients Having Open Lung Surgery. Regional Anesthesia and Pain Medicine, 36, 256-260. https://doi.org/10.1097/AAP.0b013e3182176f42

[16] Gulbahar, G., Kocer, B., Muratli, S.N., Serife, N.M., Erkan, Y., Ozlem, G., Koray, D. and Unal, S. (2010) A Comparison of Epidural and Paravertebral Catheterization Techniques in Post-Thoracotomy Pain Management. European Journal of Cardiothoracic Surgery, 37, 467-472.

[17] Tornero-Campello, G. (2007) Transversus Abdominis Plane Block Should Be Compared with Epidural for Postoperative Analgesia after Abdominal Surgery. Anesthesia \& Analgesia, 105, 281-282. https://doi.org/10.1213/01.ane.0000261299.56821.12

[18] Lin, Y.N., Li, Q., Yang, R.M., Mao, Z.X. and Liu, J.C. (2013) Addition of Dexmedetomidine to Ropivacaine Improves Cervical Plexus Block. Acta Anaesthesiologica Taiwanica, 51, 63-66. https://doi.org/10.1016/j.aat.2013.06.001

[19] Federico, R., Alessandro, R., Andrea, L., Piero, D.M., Ugo, C. and Alessandro, B.I. (2014) Analgesia in Patients Undergoing Thoracotomy, Epidural versus Paravertebral Technique. The Journal of Thoracic and Cardiovascular Surgery, 147, 469-474. https://doi.org/10.1016/j.jtcvs.2013.09.024

[20] Debreceni, G., Molnar, Z., Szelig, L. and Molnár, T.F. (2003) Continuous Epidural or Intercostals Analgesia Following Thoracotomy: A Prospective Randomized, Double-Blind Clinical Trial. Acta Anaesthesiologica Scandinavica, 47, 1091-1095. https://doi.org/10.1034/j.1399-6576.2003.00208.x

[21] Hadzic, A., Kerimoglu, B., Loreio, D., Karaca, P.E., Claudio, R.E., et al. (2006) Paravertebral Blocks Provide Superior Same-Day Recovery over General Anesthesia for Patients Undergoing Inguinal Hernia Repair. Anesthesia \& Analgesia, 102, 
1076-1081. https://doi.org/10.1213/01.ane.0000196532.56221.f2

[22] Niraj, G., Kelkar, A., Hart, E., Horst, C., Malik, D., Yeow, C., Singh, B. and Chaudhri, S. (2014) Comparison of Analgesic Efficacy of Four-Quadrant Transversus Abdominis Plane (TAP) Block and Continuous Posterior TAP Analgesia with Epidural Analgesia in Patients Undergoing Laparoscopic Colorectal Surgery: An Open-Label, Randomised, Non-Inferiority Trial. Anaesthesia, 69, 348-355.

[23] Dalim, K.B., Puneet, K. and Souvik, M. (2014) Analgesic Efficacy and Safety of Thoracic Paravertebral and Epidural Analgesia for Thoracic Surgery, a Systematic Review and Meta-Analysis. Cardio Vascular and Thoracic Surgery, 18, 626-636.

[24] Wahba, S.S. and Kamal, S.M. (2014) Analgesic Efficacy and Outcome of Transversus-Abdominis Plane Block versus Low Thoracic-Epidural Analgesia after Laparotomy in Ischemic Heart Disease Patients. Journal of Anesthesia, 28, 517-523. https://doi.org/10.1007/s00540-013-1774-6

[25] Santhosh Kumar, T. and Rajendran, R. (2003) Comparative Evaluation of Thoracic Epidural versus Thoracic Paravertebral Block for Post Thoracotomy Pain Relief with 0.25\% Bupivacaine. Indian Journal of Anaesthesia, 47, 269-274.

[26] Ding, X.B., Jin, S.Q., Niu, X.Y., Ren, H., Fu, S.K. and Li, Q. (2014) A Comparison of the Analgesia Efficacy and Side Effects of Paravertebral Compared with Epidural Blockade for Thoracotomy: An Updated Meta Analysis. PLoS One, 5, e96233.

https://doi.org/10.1371/journal.pone.0096233 